\title{
Gambaran Evaluasi Terapi Antibiotik pada Pasien Bronkopneumonia di Instalasi Rawat Inap Anak RSUP Prof. Dr. R. D. Kandou Manado Periode Juli 2017 - Juni 2018
}

\author{
${ }^{1}$ Erfand S. Polii \\ ${ }^{2}$ Christi D. Mambo \\ ${ }^{2}$ Jimmy Posangi
}

\author{
${ }^{1}$ Program Studi Pendidikan Dokter Fakultas Kedokteran Universitas Sam Ratulangi Manado \\ ${ }^{2}$ Bagian Farmakologi dan Terapi Fakultas Kedokteran Universitas Sam Ratulangi Manado \\ Email: erfandsadrakhpolii@gmail.com
}

\begin{abstract}
Bronchopneumonia is still one of the health problems worldwide due to its high mortality rate. The definitive treatment for this disease is antibiotics. However, the use of antibiotics in hospitals is $30-80 \%$ not for the right indication. This study was aimed to obtain the description of evaluation of antibiotic therapy in bronchopneumonia patients in the Pediatrics Inpatient Installation of Prof. Dr. R. D. Kandou Hospital Manado in the period of July 2017 - June 2018. This was a descriptive retrospective study with a cross-sectional design. Evaluation was done by using quantitative methods of DDD by WHO. The results of DDD/100-day evaluation using 41 samples were cefixime 141.63 DDD/100-day (48\%), ampicillin 123.51 DDD /100-day (42\%), cefotaxime 10.52 DDD/100-day (4\%), gentamicin $8.88 \mathrm{DDD} / 100$-day (3\%), chloramphenicol $8.68 \mathrm{DDD} / 100$-day (3\%), and ceftriaxone 3.06 DDD/100-day (1\%). Antibiotics included in $90 \%$ of the DU segment were cefixime and ampicillin. Conclusion: The most quantitative description evaluation of antibiotic therapy in bronchopneumonia patients was cefixime 141.63 DDD/100-day.
\end{abstract}

Keywords: antibiotics, bronchopneumonia, DDD

\begin{abstract}
Abstrak: Bronkopneumonia menjadi salah satu masalah kesehatan di dunia karena angka kematiannya yang tinggi. Pengobatan definitifnya yaitu dengan pemberian antibiotik. Di berbagai rumah sakit, ditemukan $30-80 \%$ penggunaan antibiotik tidak didasarkan pada indikasi yang tepat. Penelitian ini bertujuan untuk mengetahui gambaran evaluasi terapi antibiotik pada pasien bronkopneumonia di Instalasi Rawat Inap Anak RSUP Prof. Dr. R. D. Kandou Manado periode Juli 2017 - Juni 2018. Jenis penelitian ialah deskriptif retrospektif dengan desain potong lintang. Evaluasi menggunakan metode kuantitatif DDD oleh WHO. Hasil evaluasi antibiotik DDD/100-hari dari 41 sampel yaitu cefiksim 141,63 DDD/100-hari (48\%), ampicilin 123,51 DDD/100-hari (42\%), cefotaksim 10,52 DDD/100-hari (4\%), gentamisin 8,88 DDD/100-hari (3\%), kloramfenikol 8,68 DDD/100-hari (3\%), dan ceftriakson 3,06 DDD/100-hari (1\%). Antibiotik yang masuk dalam segmen DU 90\% yaitu cefiksim dan ampicilin. Simpulan: Secara kuantitas gambaran evaluasi terapi antibiotik terbanyak pada pasien bronkopneumonia yaitu cefiksim 141,63 DDD/100-hari.
\end{abstract}

Kata kunci: antibiotik, bronkopneumonia, DDD

Bronkopneumonia disebut juga pneumonia lobularis dinyatakan dengan adanya daerah infeksi yang bebercak dengan diameter sekitar 3-4 cm yang mengelilingi dan melibatkan bronkus. ${ }^{1}$ Pneumonia menjadi salah satu masalah kesehatan di dunia karena angka kematiannya yang tinggi. ${ }^{2,3}$ Prevalensi di Indonesia selama tahun 2013 yaitu sekitar $1,8 \%$, berdasarkan kelompok usia sendiri, ditemukan bahwa pneumonia 
lebih sering dijumpai anak pada usia 1-4 tahun dan kembali meningkat pada kelompok usia di atas 45 tahun. ${ }^{4}$ Menurut perkiraan WHO angka kematian bayi akibat pneumonia di negara berkembang yaitu 40 dari 1000 kelahiran hidup atau sekitar $15-20 \%$ pertahun, serta $10 \%$ penderita pneumonia akan meninggal bila tidak diberi pengobatan. ${ }^{2,3}$ Pengobatan definitif untuk pneumonia sendiri yaitu pemberian antibiotik.

Antibiotik sering dipakai dalam terapi penyakit infeksi yang disebabkan oleh bakteri. Pada penelitian dari tim Antimicrobial Resistance in Indonesia Prevalence and Prevention (AMRIN) menggunakan standar evaluasi kualitas antibiotik, hasil evaluasi di dua rumah sakit pendidikan di Indonesia menunjukkan hanya $21 \%$ peresepan antibiotik yang tergolong rasional. ${ }^{5}$ Menurut Kemenkes RI tahun 2011, pada penelitian tentang kualitas penggunaan antibiotik di berbagai rumah sakit, ditemukan sekitar $30-80 \%$ penggunaan antibiotik tidak didasarkan pada indikasi yang tepat. ${ }^{6,7}$

Penggunaan antibiotik yang rasional diharapkan dapat meningkatkan luaran terapi dan membatasi laju resistensi. Efek peresepan antibiotik yang kurang tepat pada pelayanan pengobatan dasar, juga dapat meningkatkan kejadian resistensi. ${ }^{8}$ Penggunaan antibiotik untuk bronkopneumonia harus selalu didasarkan pada indikasi yang baik dan tepat. Jika tidak sesuai indikasi, bisa terjadi resistensi dan memengaruhi proses penyembuhan penyakit.

Tingginya prevalensi kejadian bronkopneumonia pada anak serta sering timbulnya resistensi yang disebabkan penggunaan antibiotik yang tidak sesuai indikasi melatarbelakangi penelitian ini.

\section{METODE PENELITIAN}

Penelitian ini menggunakan metode deskriptif retrospektif dengan desain potong lintang. Evaluasi yang dilakukan menggunakan metode kuantitatif Defined Daily Dose (DDD) oleh WHO. Penelitian ini dilakukan di RSUP Prof. Dr. R. D. Kandou Manado.
Populasi pada penelitian ini yaitu pasien anak di RSUP Prof. Dr. R. D. Kandou Manado yang memenuhi kriteria inklusi. Teknik pengambilan sampel pada penelitian ini menggunakan simple random sampling, sehingga didapatkan besaran sapel sebesar 41 pasien. Cara pengambilan sampel menggunakan data sekunder yang didapatkan dari catatan rekam medik.

Data hasil penelitian diolah dan disajikan dalam bentuk tabel dan grafik. Data dianalisis menggunakan aplikasi statistik SPSS versi 24.0 dengan analisis deskriptif untuk mencari distribusi frekuensi.

\section{HASIL DAN BAHASAN}

Berdasarkan data rekam medis, didapatkan pasien dengan jenis kelamin lakilaki lebih banyak daripada perempuan yaitu 19 pasien laki-laki $(46,34 \%)$ dan 22 pasien perempuan $(53,66 \%)$ (Gambar 1$)$.

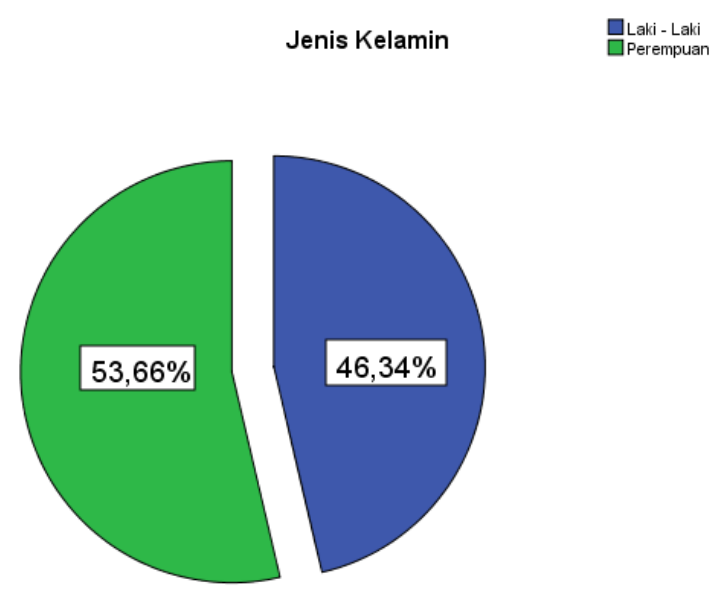

Gambar 1. Demografi berdasarkan jenis kelamin

Berdasarkan waktu perawatan, yakni sesuai dengan periode penelitian yang diambil antara Juli 2017-Juni 2018 didapatkan dari paling banyak sampai paling sedikit yaitu: Juli, Agustus, Januari, dan Mei berjumlah 5 pasien (12\%); Oktober, April, dan Juni berjumlah 4 pasien (10\%); November dan Desember berjumlah 3 pasien (7\%); serta September, Februari, dan Maret berjumlah 1 pasien (2\%) (Gambar 2). 


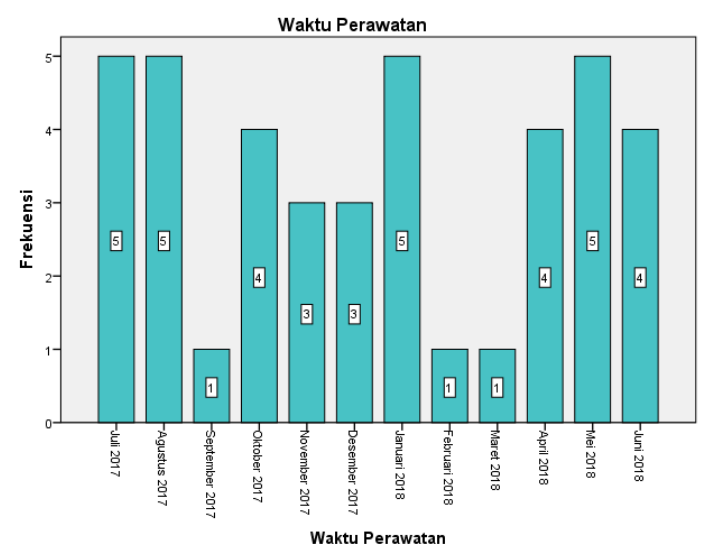

Gambar 2. Demografi berdasarkan waktu perawatan

Berdasarkan data usia pasien, terlihat bahwa pasien terbanyak yang ditemukan berusia antara 1-2 tahun (41\%), kemudian usia $>2$ bulan -1 tahun (29\%), usia 2-3 tahun (20\%), 3-4 tahun (7\%), dan paling sedikit usia 4-5 tahun (2\%) (Gambar 3).

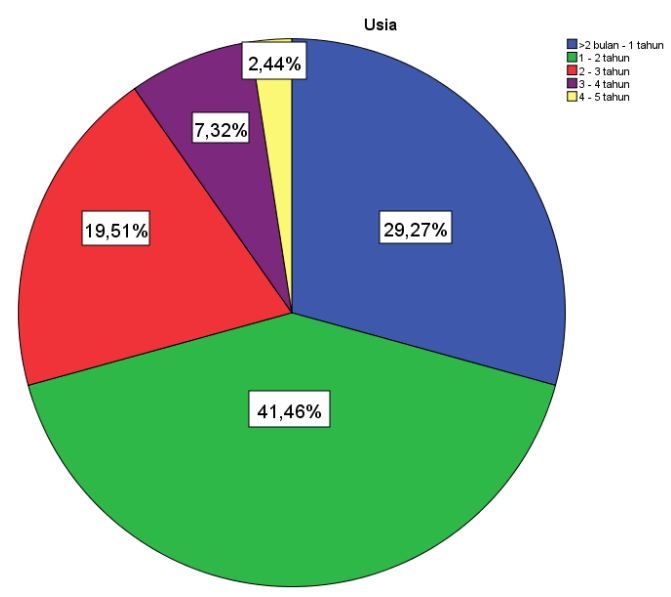

Gambar 3. Demografi persentase berdasarkan usia

Jenis antibiotik yang ditemukan sering dipakai antara lain antibiotik golongan beta-lactam (cefiksim, ampicilin, cefotaksim, ceftriakson), kloramfenikol, dan aminoglikosida (gentamisin). Berdasarkan jenis antibiotik-nya, didapatkan cefiksim paling banyak dipakai (28\%), kemudian ampicilin (26\%), kloramfenikol (18\%), gentamisin $(15 \%)$, cefotaksim $(11 \%)$, dan paling sedikit ceftriakson (3\%) (Gambar 4).

Antibiotik dengan nilai DDD tertinggi yaitu cefiksim 300,275 (48\%) dan ampicilin 261,85 (42\%) masuk dalam segmen
Drug Utilization (DU) 90\%, sedangkan sisanya yaitu kloramfenikol, cefotaksim, gentamisin, dan ceftriakson masuk dalam segmen DU 10\% (Gambar 5).

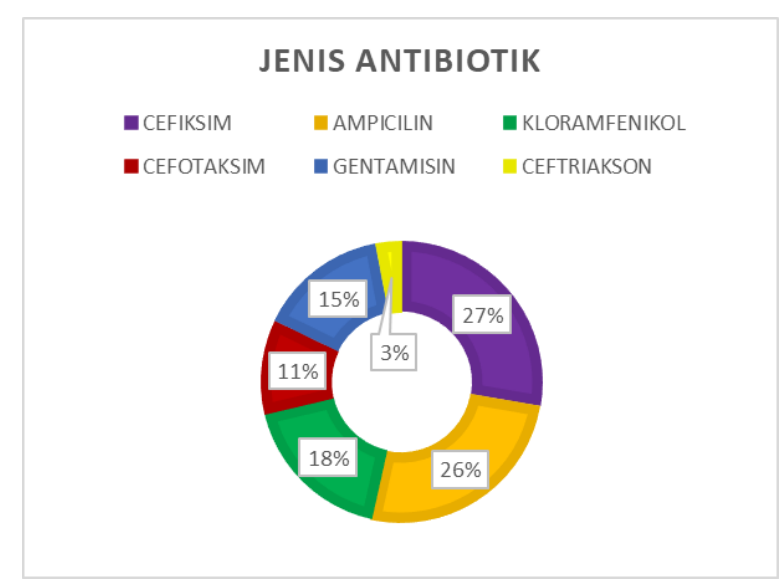

Gambar 4. Demografi penggunaan antibiotik.

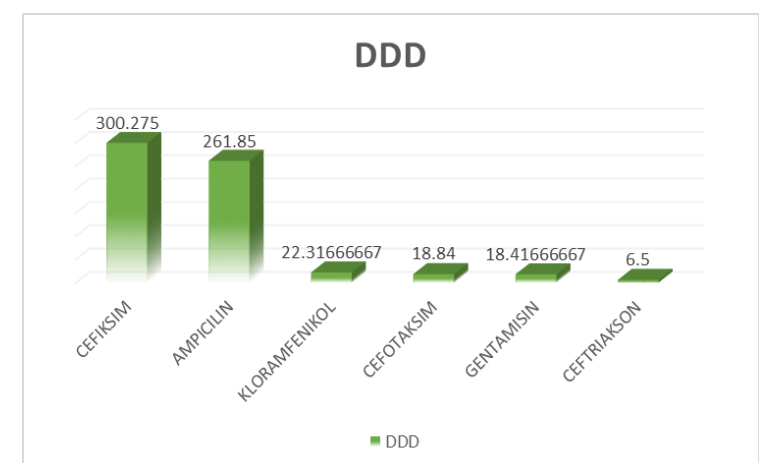

Gambar 5. DDD pada penggunaan antibiotik

Antibiotik dengan DDD/100-Hari terbanyak yaitu cefiksim 141,63 DDD/100hari (48\%) dan ampicilin 123,51 DDD/100hari $(42 \%)$ serta masuk dalam segmen DU 90\% (Gambar 6).

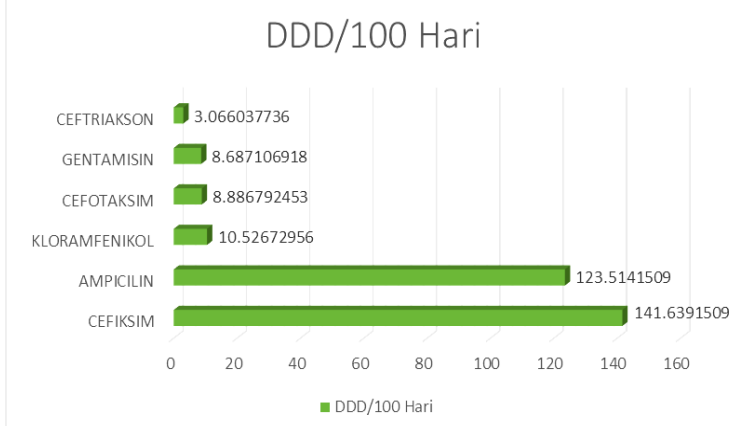

Gambar 6. DDD/100-hari.

Hal ini menunjukkan penggunaan antibiotik terbesar yaitu golongan cefalo- 
sporin generasi tiga (cefiksim) dan golongan penisilin (ampisilin).

Penelitian yang hampir serupa oleh Yanti $^{9}$ mendapatkan antibiotik tunggal yang banyak digunakan di antaranya cefiksim sebesar 33,33\%, pada 18 pasien balita penderita pneumonia rawat inap di RSUD Sultan Syarif Mohamad Alkadrie Pontianak periode Juli 2014-Juni 2015.

Pada penelitian yang dilakukan oleh Febriana $^{10}$ di bangsal anak, didapatkan penggunaan antibiotik terbesar berasal dari golongan sefalosporin generasi tiga yang lain yaitu ceftriakson dengan total penggunaan sebesar 39,4 DDD/100.

Penelitian lain oleh Rahayu et $\mathrm{al}^{11}$ dengan menggunakan evaluasi kualitatif Gyssen menunjukkan bahwa seftriakson merupakan antibiotik yang banyak digunakan $(29,8 \%)$ sedangkan penelitian yang dilakukan oleh Utsman ${ }^{12}$ melaporkan bahwa jenis antibiotik yang banyak digunakan antara lain cefotaksim $(89,80 \%)$.

Penggunaan kedua jenis antibiotik ini (cefiksim dan ampicilin) banyak ditemukan pada penelitian karena sesuai dengan penggunaan Fornas di rumah sakit dalam pelaksanaan Jaminan Kesehatan Nasional (JKN). ${ }^{13}$

Berdasarkan pedoman WHO, penggunaan antibiotik tunggal yang harus digunakan yaitu golongan penisilin (ampisilin) dan sefalosporin (sefiksim). Kedua golongan antibiotik ini merupakan broad spectrum yang memiliki aktifitas baik terhadap bakteri Gram negatif maupun Gram positif dan aktif melawan S. Pneumoniae.

Penilaian terhadap obat yang masuk ke dalam segmen DU 90\% diperlukan untuk menekankan segmen obat tersebut dalam hal evaluasi, pengendalian penggunaan dan perencanaan pengadaan obat. ${ }^{14}$

\section{SIMPULAN}

Berdasarkan hasil penelitian ini dapat disimpulkan bahwa jumlah keseluruhan DDD yaitu 628,19 dengan antibiotik tertinggi yaitu cefiksim 300,275 DDD. Pada evaluasi DDD/100-hari, jumlah keseluruhan yaitu 296,319 dengan jenis antibiotik tertinggi yaitu cefiksim 141,63
DDD/100-hari (48\%). Antibiotik yang masuk dalam segmen DU 90\% antara lain cefiksim dan ampicilin.

Antibiotik yang paling banyak dipakai sebagai terapi bronkopneumonia ialah cefiksim sedangkan yang paling sedikit dipakai ialah ceftriakson.

\section{SARAN}

Disarankan untuk melakukan penelitian lanjut mengenai gambaran evaluasi antibiotik pada pasien bronkopneumonia di Instalasi Rawat Inap anak RSUP Prof Dr R $D$ Kandou Manado dengan metode evaluasi kualitatif.

Perlu dilakukan penelitian dengan metode pendekatan lain karena metode pendekatan restrospektif memiliki kelemahan pada data rekam medik yang tidak lengkap yang banyak dijumpai pada penelitian ini.

\section{DAFTAR PUSTAKA}

1. Price SA. Patofisiologi: Konsep Klinis Proses Perjalanan Penyakit. Jakarta: EGC, 2012.

2. Khasanah FNUR. Asuhan Keperawatan pada an. V dengan Pneumonia di Ruang Kanthil Rumah Sakit Umum Daerah Banyumas [Diploma tesis]. Purwokerto: Universitas Muhammadiyah Purwokerto; 2017.

3. WHO, UNICEF. Pneumonia: the forgotten killer of children. Geneva: WHO Press, 2012.

4. Badan Penelitian dan Pengembangan Kesehatan. Riset kesehatan dasar tahun 2013. Jakarta: Kementerian Kesehatan RI, 2013.

5. Departemen Kesehatan RI. Pharmaceutical Care untuk Penyakit Infeksi Saluran Pernapasan. Jakarta: Departemen Kesehatan RI, 2005.

6. Purwaningsih AEDA, Rahmawati F, Wahyono D. Evaluasi penggunaan antibiotik pada pasien Pediatri Rawat Inap. Jurnal Manajemen dan Pelayanan Farmasi. 2015;5(3):211-8.

7. Kemenkes RI. Peraturan Menteri Kesehatan Republik Indonesia Nomor 2406. Jakarta: Kementerian Kesehatan RI, 2011.

8. Khairunissa R, Hajrah, Rusli R. Profil 
penggunaan antibiotik pada pasien ISPA di beberapa puskesmas Kota Samarinda. Proceeding of Mulawarman Pharmaceuticals Conferences ke-4, 2021 Oktober 2016. Samarinda: Fakultas Farmasi Universitas Mulawarman, 2016; p. 316-21.

9. Yanti Y, Nurmainah, Hariyanto IH. Rasionalitas penggunaan antibiotik pada pasien rawat inap balita penderita pneumonia dengan pendekatan metode Gyssens di RSUD Sultan Syarif Mohamad Alkadrie Pontianak. Pontianak: Universitas Tanjungpura; 2016.

10. Febiana T. Kajian rasionalitas penggunaan antibiotik di intensive care unit RSUP Dr. Kariadi Semarang Periode AgustusDesember 2011 [Karya tulis ilmiah]. Semarang: Universitas Dipenogoro; 2012.

11. Rahayu YD, Wahyono D, Mustofa.
Evaluasi rasionalitas penggunaan antibiotik terhadap luaran pada pasien anak penderita pneumonia. Jurnal Manajemen dan Pelayanan Farmasi; 2014;4(4):264-70.

12. Utsman P. Evaluasi penggunaan antibiotik pada balita penderita pneumonia rawat inap di RSUD Tidar Kota Magelang tahun 2016 [Skripsi]. Surakarta: Universitas Muhammadiyah Surakarta; 2016.

13. Kemenkes RI. Keputusan Menteri Kesehatan RI No. HK.01.07/ MENKES/659/2017 tentang Formula-rium Nasional. Jakarta: Kementerian Kesehatan RI, 2017.

14. Mahmudah F, Sumiwi S, Hartini S. Studi penggunaan antibiotik berdasarkan ATC/DDD dan DU $90 \%$ di Bagian Bedah Digestif di salah satu rumah sakit di Bandung. Jurnal Farmasi Klinik Indonesia. 2016;5(4):293-8. 